\title{
Correction to: Task sharing for the care of severe mental disorders in a low-income country (TaSCS): study protocol for a randomised, controlled, non-inferiority trial
}

Charlotte Hanlon ${ }^{1,2^{*}}$, Atalay Alem ${ }^{1}$, Girmay Medhin ${ }^{3}$, Teshome Shibre $^{4}$, Dawit A. Ejigu ${ }^{5}$, Hanna Negussie ${ }^{1}$ Michael Dewey ${ }^{2}$, Lawrence Wissow ${ }^{6}$, Martin Prince ${ }^{2}$, Ezra Susser ${ }^{7,8}$, Crick Lund ${ }^{2,9}$ and Abebaw Fekadu ${ }^{1,10}$

\section{Correction to: Trials 17, 76 (2016) \\ https://doi.org/10.1186/s13063-016-1191-x}

Following publication of the original article [1], the authors notified us that they mistakenly indicated they would report medication adherence as a trial outcome measured by the Morisky Medication Adherence Scale. However, the authors will no longer use this measure of adherence in the TaSCS trial analysis.

\section{Author details}

'Addis Ababa University, College of Health Sciences, School of Medicine, Department of Psychiatry, Addis Ababa, Ethiopia. Institute of Psychiatry, Psychology and Neuroscience, Centre for Global Mental Health, King's College, London, UK. ${ }^{3}$ Aklilu Lemma Institute of Pathobiology, Addis Ababa University, Addis Ababa, Ethiopia. ${ }^{4}$ Horizon Health Network, Dr Everett Chalmers Regional Hospital, Psychiatry, Fredericton, New Brunswick, Canada. ${ }^{5}$ Department of Pharmacology, St Paul's Hospital Millennium Medical College, Addis Ababa, Ethiopia. ${ }^{6}$ Department of Health, Behaviour and Society, Johns Hopkins School of Public Health, Baltimore, MD, USA. ${ }^{7}$ Mailman School of Public Health, Columbia University, New York, USA. ${ }^{8}$ New York State Psychiatric Institute, New York, USA. ${ }^{9}$ Department of Psychiatry and Mental Health, Alan J. Flisher Centre for Public Mental Health, University of Cape Town, 46 Sawkins Road, Rondebosch, Cape Town, South Africa.

${ }^{10}$ Department of Psychological Medicine, Institute of Psychiatry, King's College London, Psychology and Neuroscience, Centre for Affective Disorders, London, UK.
Published online: 06 October 2020

\section{Reference}

. Hanlon C, et al. Task sharing for the care of severe mental disorders in a low-income country (TaSCS): study protocol for a randomised, controlled, non-inferiority trial. Trials. 2020;17:76. https://doi.org/10.1186/s13063-016$1191-\mathrm{x}$.

The original article can be found online at https://doi.org/10.1186/s13063016-1191-x.

* Correspondence: charlotte.hanlon@kcl.ac.uk

'Addis Ababa University, College of Health Sciences, School of Medicine, Department of Psychiatry, Addis Ababa, Ethiopia

${ }^{2}$ Institute of Psychiatry, Psychology and Neuroscience, Centre for Global Mental Health, King's College, London, UK

Full list of author information is available at the end of the article

(c) The Author(s). 2020 Open Access This article is licensed under a Creative Commons Attribution 4.0 International License, which permits use, sharing, adaptation, distribution and reproduction in any medium or format, as long as you give appropriate credit to the original author(s) and the source, provide a link to the Creative Commons licence, and indicate if changes were made. The images or other third party material in this article are included in the article's Creative Commons licence, unless indicated otherwise in a credit line to the material. If material is not included in the article's Creative Commons licence and your intended use is not permitted by statutory regulation or exceeds the permitted use, you will need to obtain permission directly from the copyright holder. To view a copy of this licence, visit http://creativecommons.org/licenses/by/4.0/ The Creative Commons Public Domain Dedication waiver (http://creativecommons.org/publicdomain/zero/1.0/) applies to the data made available in this article, unless otherwise stated in a credit line to the data. 